\title{
GUSTAVO ZAGREBELSKY, JUEZ CONSTITUCIONAL
}

Miguel Carbonell

IIJ-UNAM

No es frecuente que, fuera del ámbito del derecho anglosajón, los más altos funcionarios judiciales escriban sobre su experiencia práctica en la impartición de justicia. En Estados Unidos la biografía judicial (o la autobiografía) es casi un género literario por sí mismo. Son muy conocidas las biografías de los jueces más renombrados de su historia, como John M arshall, Oliver Wendell Holmes, Hugo Black, William O. Douglas, Earl Warren, Felix Frankfurter, William Brennan, Harry Blackmun o Sandra Day O'Connor. No existe nada parecido a eso en el derecho de los países latinos. No lo hay en Italia, ni en Francia, Alemania, España o en América Latina.

Por eso debe saludarse el hecho de que Gustavo Zagrebelsky, el eminente juez de la Corte Constitucional italiana y uno de los teóricos más influyentes del movimiento neoconstitucionalista, haya publicado un pequeño libro de reflexiones a partir de su desempeño en la judicatura. ${ }^{1}$ No se trata de una autobiografía, sino de la exposición de sus percepciones sobre el papel del juez y el lugar de las cortes constitucionales dentro de los sistemas democráticos. El libro tiene por objeto, en palabras del autor, ofrecer a los lectores "el recuerdo de una experiencia que he tenido la fortuna de vivir junto a los colegas con los que he compartido el trabajo y la fatiga, las jornadas y las tensiones de nueve años".

Llama la atención Zagrebelsky sobre un hecho que acontece no solamente en Italia, sino en casi todos los países de la tradición romano-germánica: pese a la importante posición institucional que tiene la Corte Constitucional en Italia, es una de las institucio-

1 Zagrebelsky, Gustavo, Principios y votos. El Tribunal Constitucional y la política, traducción de Manuel Martínez Neira, Madrid, Trotta, 2008, 109 pp. 
nes menos conocidas por los ciudadanos. Lo mismo sucede en México con nuestra Corte Suprema, cuyos integrantes son desconocidos para gran parte de la o pinión pública nacional, pese a que todos los días toman decisiones vitales sobre nuestros derechos fundamentales o sobre la configuración presente y futura de la democracia mexicana.

También apunta nuestro autor la aparente paradoja de que la función de la Corte es política, pero no pertenece a la política; tiene mucho que ver con la democracia, pero no deriva de ella. Esto en parte es así debido a que la Corte tiene por misión fundamental aplicar la Constitución, que es una norma que contiene todo aquello que no está sujeto a votación alguna. 0 mejor dicho, la Constitución contiene todo sobre lo que ya no se vota, porque "ha sido votado de una vez por todas en su origen". La Constitución se sitúa (debe situarse) por encima de la batalla política cotidiana. No puede ser convertida en rehén de ningún partido político y de ningún programa de gobierno. La Constitución configura y supone un patrimonio cultural que debe ser compartido por todos.

Zagrebelsky apunta que la principal función de un texto constitucional es "fijar los presupuestos de la convivencia, es decir, los principios sustanciales de la vida común y las reglas del ejercicio del poder público aceptados por todos, situados por ello fuera, incluso por encima, de la batalla política... La Constitución fija en primer lugar el pactum societatis, con el cual se acuerdan las condiciones de la convivencia, en ese recíproco respeto que protege del conflicto extremo, es decir, de la guerra civil".

En el ejercicio de la función jurisdiccional que tiene por objeto el control de constitucionalidad de las leyes y demás actos de los poderes públicos se da una paradoja adicional que es discutida por Zagrebelsky en su libro. La Constitución contiene aquello sobre lo que no se vota, pero los jueces la interpretan y la aplican votando a su vez. ¿Se trata de una contradicción?, se pregunta el autor.

Y eso da pie para que nos explique una de las varias cuestiones llamativas o curiosas del funcionamiento de la Corte Constitucional italiana. Los trabajos de sus magistrados son secretos, en el sentido de que no hay audiencias públicas y de que las deliberaciones son a puerta cerrada. Además, a diferencia de la casi totalidad de cortes constitucionales del mundo, no existe la figura de los votos particulares. Todas las decisiones se toman por el cuerpo colegiado como tal, sin que exista la posibilidad de que un magistrado exprese razones concurrentes o disidentes sobre el sentido del fallo.

Zagrebelsky justifica esta peculiaridad aduciendo que de esa forma se proyecta hacia fuera un fuerte sentido de unidad del tribunal. Además, de esa manera se protege la colegialidad de los trabajos de los magistrados al interior de la Corte, ya que saben que no tienen cada uno de ellos voz propia, sino que deben necesariamente hablar como tribunal: "mientras que en otros países los jueces constitucionales están dotados de personalidad propia e individualidad institucional, en Italia los jueces constitucionales -a los que se reconoce la más plena subjetividad dentro del colegio- no son nada fuera del Tribunal. Sólo existen como parte del Tribunal... El carácter colegial y unitario del Tribunal asume un particular significado por la ausencia de votos particu- 
lares... La razón más profunda hay que buscarla en la exigencia de unidad: uno de los tantos valores de la colegialidad".

Un observador externo, al leer esta justificación, no puede dejar de preguntarse si un Tribunal Constitucional gana o pierde al no permitirles a sus integrantes expresar desacuerdos o líneas de justificación distintas a las que ofrece la mayoría. La historia nos ofrece abundantes ejemplos en los que se acredita la certera caracterización de Peter Häberle, según la cual los votos disidentes son la jurisprudencia constitucional (alternativa) del futuro.

¿Qué destino le habría esperado a la libertad de expresión sin los atinados votos particulares de Oliver Wendell Holmes en los primeros años del siglo pasado?, ¿qué habría sido de la Corte de los Estados Unidos sin la disidencia liberal de John Paul Stevens o de William Brennan en la sofocante atmósfera conservadora de las Cortes presididas por Rehnquist y Roberts?, ¿qué papel habría jugado el Tribunal Constitucional español sin la permanente llamada al orden que supusieron, en sus primeros años de existencia, los cientos de votos particulares, magistrales todos, de Francisco Rubio Llorente? ${ }^{3}$ ¿Cómo podríamos entender hoy en día el papel de la Suprema Corte de M éxico sin tener acceso y registro de los votos disidentes, que también deben sumar centenares ya, del ministro José Ramón Cossío, que en tantos temas ha sido un adelantado al criterio de sus colegas? ${ }^{4}$ Puede ser que el esquema de hablar con una sola voz haya funcionado en Italia, pero seguramente no se trata de un ejemplo a seguir.

Nos advierte también Zagrebelsky sobre la permanente tentación que tienen algunos jueces constitucionales para abandonar "subrepticiamente" ciertos precedentes, sin poner de manifiesto que lo están haciendo y sin ofrecer argumentos que justifiquen el nuevo criterio. Reconoce el autor que "Las contradicciones jurisprudenciales no favorecen la reputación del Tribunal", pero también señala que la autoridad del propio Tribunal se ve fortalecida cuando un cambio de criterio se adopta expresamente, sin intentar enmascararlo a través "de un uso no objetivo de los precedentes, como si se avergonzase de lo que hace". Esta advertencia es muy importante, ya que conocemos ejemplos en muchos países de verdaderos revirements jurisprudenciales que no se asumen como tales. Algunos jueces deciden abandonar el pasado sin enfrentársele directamente. Quieren crear nueva jurisprudencia metiendo los criterios renovados por la puerta de atrás de las sentencias. Tenemos ejemplos recientes de esta actitud poco ética en Estados Unidos ${ }^{5}$ y en México.

2 Algunos de los más grandes y polémicos votos disidentes en la historia de la Corte estadounidense pueden encontrarse en TuSHNET, Mark, I dissent. Great opposing opinions in ladmark Supreme Court cases, Beacon Press, Boston, 2008.

3 Ver Bravo Gala, Pedro, "Algunas consideraciones obvias acerca de la actividad jurisdiccional del profesor Rubio Llorente" en La democracia constitucional. Estudios en homenaje al Profesor Francisco Rubio Llorente, Madrid, CEPC, 2002, tomo II, pp. 1889 y ss.

4 Cossío Díaz, José Ramón, Votos, Universidad de Colima, Editorial Laguna, México, 2006.

5 Ronald Dworkin ha analizado y criticado esta actitud por algunos de los integrantes de la Corte Roberts en Estados Unidos; ver su libro The Supreme Court phalanx. The court's new right-wing bloc, New York review books, Nueva York, 2008. 
Hay que ser claros en este punto: desde luego que un juez puede cambiar de opinión, incluso un juez del más alto tribunal de un país, un juez que trabaja sobre temas de enorme importancia y cuyas decisiones deben ser calibradas y pensadas hasta el más mínimo detalle. Pero si va a llevar a cabo ese cambio de criterio, debe hacerlo de forma expresa: primero reconociendo que está abandonando un precedente y luego ofreciendo razones que justifiquen, que den fundamento a la nueva interpretación.

Zagrebelsky destaca también en su libro la necesidad de que los jueces constitucionales sean independientes de sí mismos. Se trata de un tema poco explorado, pero sobre el que vale la pena detenerse. Nuestro autor nos recuerda que los jueces constitucionales son hombres y mujeres comunes y corrientes: "No hay nada que diferencie a los jueces del resto de los mortales". Pero en el desempeño del cargo deben asumir una actitud que no tienen todas las demás personas: deben ser fieles a la Constitución, de tal suerte que el texto constitucional pase a formar parte de sus hábitos mentales y morales.

Nos recuerda Zagrebelsky el caso de un famoso juez de la Corte estadounidense, Felix Frankfurter, quien fue el redactor de la sentencia del caso Gobitis, de acuerdo con la cual se permitía sancionar a los niños que no saludaran a la bandera por motivos religiosos. La decisión del caso Gobitis desató una ola de ataques contra miembros de los Testigos de Jehová y varios de sus lugares de reunión fueron quemados; en el rechazo a esa violencia y al sentido del fallo, la sociedad norteamericana tomó muy en cuenta la actitud de Hitler manipulando al pueblo alemán para que adorara a su bandera y a los símbolos nazis. La Corte cambió de criterio poco tiempo después, en la sentencia del caso Barnette, redactada por el más elocuente juez en to da la historia de la Corte, Robert H. Jackson, quien escribió pasajes verdaderamente memorables en su resolución. ${ }^{6}$ Frankfurter escribió entonces un poderoso voto disidente en el que ponía de manifiesto su religión judía y el carácter de perseguidos históricos de sus miembros; sin embargo, aseguraba, que sus propios sentimientos no podían ponerse por encima de sus deberes como juez constitucional.

Frankfurter afirmó en su voto: "Nunca se insistirá bastante en esta idea: cuando se ejercen funciones jurisdiccionales, se deben dejar aparte las propias opiniones sobre las virtudes o los vicios de una determinada ley. La única cosa que debe tomarse en consideración es si el legislador pudo razonablemente dictar tal ley". ${ }^{7}$ Es un recordato-

\footnotetext{
6 En esa sentencia Jackson puso frases como las siguientes: “Quienes comienzan por eliminar por la fuerza la discrepancia terminan pronto por eliminar a los discrepantes. La unificación obligatoria del pensamiento y de la opinión sólo obtiene unanimidad en los cementerios... El poder público es el que debe ser controlado por la opinión de los ciudadanos, y no al contrario... Si hay alguna estrella inamovible en nuestra constelación constitucional es que ninguna autoridad pública, tenga la jerarquía que tenga, puede prescribir lo que sea ortodoxo en política, religión, nacionalismo u otros posibles ámbitos de la opinión de los ciudadanos, ni obligarles a manifestar su fe o creencia en dicha ortodoxia, ya sea de palabra o con gestos. No se nos alcanza ninguna circunstancia que pueda ser considerada una excepción a esta regla".

7 Los pasajes más interesantes de la sentencia y del voto particular de Frankfurter puede verse en BELTRÁN DE FELIPE, Miguel y González García, Julio V., Las sentencias básicas del Tribunal Supremo de los Estados Unidos de América, Madrid, CEPC, BOE, 2005, pp. 255-262.
} 
rio que deberían leer muchos jueces constitucionales, todos los días. Lo que nos dice Frankfurter es que un juez constitucional no está en el cargo para expresar opiniones propias, ni para verter sus prejuicios ideológicos y religiosos en las sentencias que dicta, sino para aplicar la Constitución, que representa su único parámetro de legitimidad y su única fuente de regulación. Nada más que la Constitución puede inspirar sus actos y guiar sus criterios jurídicos.

Zagrebelsky apunta también que la independencia frente a sí mismo debe ser observada cuando un juez cae en la tentación de hacer que sus posturas doctrinales, previamente expresadas en conferencias, artículos o libros, se vuelvan las posturas del tribunal. Es una advertencia que tiene sentido y que nos recuerda, como lo señala también el autor, que el origen profesional de los jueces (como jueces inferiores, catedráticos destacados, funcionarios públicos), no debe marcar su trayectoria jurisdiccional posterior. Todos los jueces superiores tienen un origen muy claro, pero "¿Se puede decir que están en el Tribunal para representar a las categorías profesionales de las que provienen? Ciertamente no". Su tarea en el Tribunal ni siquiera consiste en representarse a sí mismos.

Finalmente, Zagrebelsky cierra su ensayo recordando que los jueces constitucionales no deben estar atados a lo que les dicte la opinión pública. A lo mejor a veces, muchas veces incluso, deben tomar decisiones impopulares. No deben ceder frente a ningún tipo de presión, una vez que estén convencidos de que están aplicando correctamente el texto de la Constitución. Escribe Zagrebelsky: "Si cedieran a la tentación de recurrir al consenso popular, no sólo traicionarían completamente su función sino que se dejarían seducir por cantos de sirena que los conducirían al desastre". Y nos recuerda una cita bíblica que justifica tal advertencia: "No seguirás a la mayoría para hacer el mal" (Éxodo, 23, 2).

Los jueces constitucionales deben militar en el "partido de la Constitución", el cual se ubica más allá de los partidos políticos. Su ánimo debe estar guiado solamente, todos los días y en todo momento, por la "voluntad de Constitución", por un compromiso personal indeclinable de hacer valer en la realidad, frente a todo y frente a todos, lo que ordena la Constitución.

En nuestros días existe un compromiso importante de observar la "obligación de alimentar el deseo de Constitución y de saciarnos"; una obligación que "alcanza a todos", pero que se refiere "en primer lugar a los jueces constitucionales". ¿Cómo hacerlo?, se pregunta Zagrebelsky: "a través de la jurisprudencia, una jurisprudencia que no se contemple a sí misma, que sepa hablar con claridad y, en general, que no tema proclamar netamente los principios esenciales que la sostienen y argumentar su importancia en la vida civil, para convertirse así en fuerza viva de la historia y de la cultura constitucional". Esa es la jurisprudencia que aspiramos a tener en México y en buena parte de América Latina. Lo complicado es que tendremos que llegar a ella sin poder contar con la fortuna de tener jueces constitucionales como Gustavo Zagrebelsky. 